We have previously described the usefulness of carotid artery repair during an emergency operation for a patient with acute aortic dissection and cerebral malperfusion. ${ }^{4} \mathrm{Be}$ cause of very poor outcome, ${ }^{1}$ however, emergency aortic surgery for such patients is often evaded. In this comatose patient life-threatening bleeding with profound shock prompted surgical intervention, and a concomitant operation for the aorta and the carotid artery was performed, although it was unknown whether removal of the thrombus in the carotid artery might ameliorate his neurologic deficits. Surgical intervention for PAU is not very uncommon. Some recent studies show the benefits of the operation in patients with acute aortic dissection and evident neurologic deficits, ${ }^{5}$ but no article is available that describes aggressive concomitant surgery for the aorta and the carotid artery. Severe hypotension or impaired organ perfusion generally accompanies acute aortic syndrome and can cause unexpected clot formation, although increased platelet count might have been another important prerequisite in this case. If the thrombus was left unnoticed and only surgical interven- tion for the PAU was performed in this patient, fatal brain malperfusion would have surely developed. In patients with acute aortic syndrome and neurologic deficits, we should have high indices of suspicion of thrombi in the aorta and other vessels, and preoperative duplex scanning of the carotid arteries is mandatory. We strongly recommend scanning of the carotid arteries before placing a central venous catheter and consideration of concomitant surgery for the aorta and the carotid artery, if indicated.

\section{References}

1. Hagan PG, Nienaber CA, Isselbacher EM, et al. New insights into an old disease. JAMA. 2000;283:897-903.

2. Coady MA, Rizzo JA, Hammond GL, Pierce JG, Kopf GS, Eleftriades JA. Penetrating ulcer of the thoracic aorta: what is it? How do we recognize it? How do we manage it? J Vasc Surg. 1998;27:1006-16.

3. Troxler M, Mavor AI, Homer-Vanniasinkam S. Penetrating atherosclerotic ulcers of the aorta. Br J Surg. 2001;88:1169-77.

4. Imanaka K, Nishimura M, Masuoka A, et al. Lethal thrombus in the carotid artery during operation for acute aortic dissection with cerebral malperfusion. Ann Thorac Surg. 2004;77:1448-9.

5. Marco P, Passalunghi D, Moneta A, et al. Coma might not preclude emergency operation in acute aortic dissection. Ann Thorac Surg. 2006;81:1348-52.

\title{
Video-assisted cardioscopy in the repair of persistent mitral paraprosthetic leak
}

\author{
Narain Moorjani, MD, FRCS, Jack Broadhurst, MB ChB, and Sunil Ohri, MD, FRCS, Southampton, \\ United Kingdom
}

Paraprosthetic leak after mitral replacement varies between $2 \%$ and $17 \%$. The risk factors implicated in its cause include continuous suture techniques, annular calcification, and replacement in the presence of infective endocarditis. Although several surgical treatment options exist, including direct suturing, suturing an autologous pericardial patch, or rereplacement, each can be associated with recurrence. This is in part due to the access to the mitral valve annulus in patients undergoing redo mitral surgery. In this case report such a patient with a recurrent mitral paraprosthetic leak is

\footnotetext{
From the Department of Cardiothoracic Surgery, Southampton General Hospital, Southampton, United Kingdom.

Received for publication May 8, 2008; accepted for publication May 25, 2008; available ahead of print Sept 22, 2008.

Address for reprints: Narain Moorjani, MD, FRCS, c/o Mr S Ohri's secretary, Department of Cardiothoracic Surgery, Southampton General Hospital, Southampton, SO166YD, United Kingdom (E-mail: narain.moorjani@doctors.org.uk).

J Thorac Cardiovasc Surg 2009;138:773-4

0022-5223/\$36.00

Copyright (c) 2009 by The American Association for Thoracic Surgery

doi:10.1016/j.jtcvs.2008.05.064
}

described, in whom use of intraoperative video-assisted cardioscopy aided the closure of a paraprosthetic lesion.

\section{CLINICAL SUMMARY}

Ten years previously, a 72-year-old man had been given a diagnosis of severe mitral regurgitation caused by the flail $\mathrm{P} 2$ segment of his posterior mitral valve leaflet. This was initially treated with quadrangular resection of $\mathrm{P} 2$ and sliding annuloplasty. Unfortunately, in the postoperative period, moderate mitral regurgitation was observed, and the valve was replaced with a $27-\mathrm{mm}$ mechanical prosthesis $(\mathrm{St}$ Jude, St Paul, Minn). Access to the mitral valve had been difficult, and hence a transseptal approach was used. Within a year, the patient became symptomatic again, and echocardiographic analysis demonstrated a significant paraprosthetic leak in the anterior aspect of his mitral valve. Operative findings included 2 holes in the anterior paravalvular region ( 5 and $2 \mathrm{~mm}$, respectively). These were closed with pledgeted horizontal mattress 2-0 Ethibond sutures (Ethicon, Inc, Somerville, NJ) to good effect. Nine years 


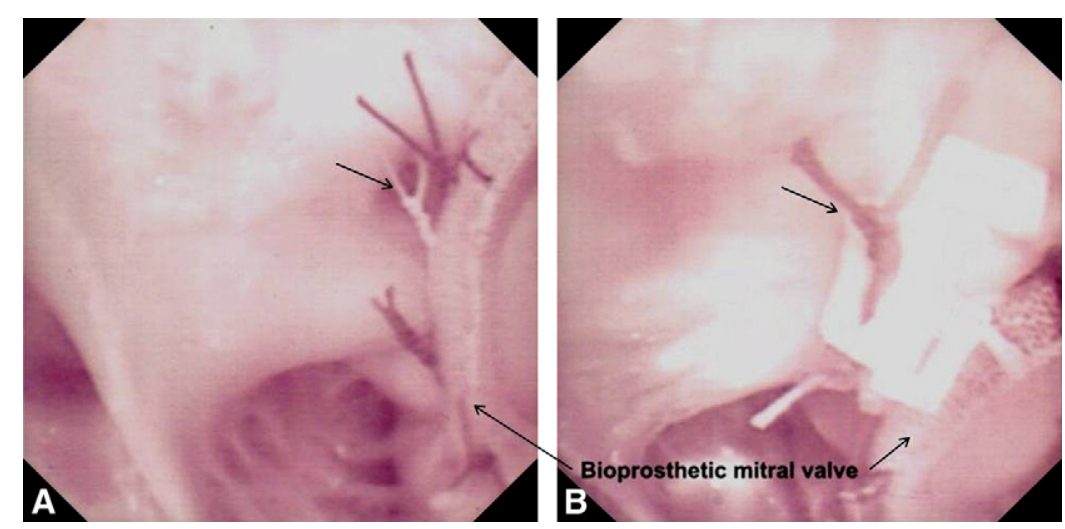

FIGURE 1. Cardioscopic images demonstrating the paraprosthetic lesion (black arrow) in the anterior part of the mitral valve annulus visualized with the aid of a cardioscope when the left ventricle was distended with saline (A) and after closure of the lesion with pledgeted 2-0 Ethibond (black arrow) sutures, with no paraprosthetic leak when the left ventricle is distended with saline (B).

later, after the third mitral valve procedure, the patient presented again with progressive dyspnea and lethargy.

Subsequent echocardiographic analysis revealed severe paraprosthetic mitral regurgitation in the anterior region of the annulus and slight lifting of the valve. In view of this, he underwent a fourth redo median sternotomy followed by institution of cardiopulmonary bypass through the aortic arch and bicaval venous cannulation, systemic cooling to $32^{\circ} \mathrm{C}$, and antegrade intra-aortic cold blood cardioplegia to arrest the heart. Access again was made difficult because of the dense adhesions. After left atriotomy, there was no obvious dehiscence visible, and therefore we elected to explant the mechanical prosthesis and replace it with a $27-\mathrm{mm} \mathrm{CE}$ Perimount bioprosthesis (Edwards Lifesciences, Irvine, Calif) with interrupted pledgeted 2-0 Ethibond sutures. However, postbypass transesophageal echocardiographic analysis revealed a residual paraprosthetic leak. Because no site could be found under direct vision, a sterile flexible bronchoscope was covered in a sterile clear plastic sleeve and used to aid visualization of the leak (Figure 1,A). With the scope in position, the left ventricle was distended with saline, and a clear paraprosthetic leak could be identified, again in the anterior aspect of the mitral valve annulus. This was closed with pledgeted 2-0 Ethibond sutures placed under cardioscopicguided vision. The left ventricle was then distended again, demonstrating no leak on the cardioscope (Figure 1,B). Postbypass transesophageal echocardiographic analysis and postoperative transthoracic echocardiographic analysis confirmed a well-seated mitral valve prosthesis with no paravalvular leak. At 2 months' follow-up, the patient remains well and in New York Heart Association functional class II.

\section{DISCUSSION}

Video-assisted cardioscopy has been described in several case reports in a variety of conditions. These include tumors ${ }^{1}$ or thrombus ${ }^{2}$ within the left ventricle, closure of atrial septal defects $^{3}$ and other congenital cardiac lesions, ${ }^{4}$ and myomec- tomy through the aortic valve. ${ }^{5}$ To the best of our knowledge, this report describes the first use of video-assisted cardioscopy in locating and treating mitral paraprosthetic leaks. In this case the use of an easily adapted flexible bronchoscope facilitated location of the position of a persistent paraprosthetic leak that was difficult to find because of poor access after the fourth redo mitral valve operation. Under direct vision with the scope, the lesion could be sutured and subsequently tested by using saline distension of the left ventricle. Other options at the time would have included a more invasive approach with an additional transseptal incision to gain greater access but with the inherent problems of incision closure. The use of the video-assisted cardioscope also facilitates direct vision by improving the lighting to this difficult-to-access part of the mitral valve annulus. Although the majority of paraprosthetic leaks are accessible through conventional methods of access, it is important to have alternative resources to deal with patients with restricted access. With the advent of minimally invasive mitral valve surgery with rigid thoracoscopic equipment, the additional use of a flexible cardioscope might facilitate the surgical repair process in those patients with difficult access.

In conclusion, this report describes the use of video-assisted cardioscopy for locating and treating mitral paraprosthetic leaks. It should be added to the surgical armamentarium for persistent and difficult-to-locate paraprosthetic leaks.

\section{References}

1. Greco E, Mestres CA, Cartañá R, Pomar JL. Video-assisted cardioscopy for removal of primary left ventricular myxoma. Eur J Cardiothorac Surg. 1999;16:677-8.

2. Mazza IL, Jacobs JP, Aldousany A, Chang AC, Burke RP. Video-assisted cardioscopy for left ventricular thrombectomy in a child. Ann Thorac Surg. 1998;66: 248-50.

3. Inoue Y, Yozu R, Mitsumaru A, Ueda T, Kawada S. Video-assisted cardioscopic staple closure for atrial septal defect. Artif Organs. 1997;21:1303-5.

4. Burke RP, Michielon G, Wernovsky G. Video-assisted cardioscopy in congenital heart operations. Ann Thorac Surg. 1994;58:864-8.

5. Bauer EP, Reuthebuch OT, Roth M, Skwara W, Klövekorn WP. Video-assisted resection of hypertrophied and fibrous intraventricular tissue. Ann Thorac Surg. 1997;63:1180-2. 